\title{
OPEN School environment and physical activity in adolescents from São Paulo city
}

\author{
Gerson Ferrari ${ }^{1 凶}$, Leandro F. M. Rezende ${ }^{2}$, Alex A. Florindo ${ }^{3,4}$, Grégore I. Mielke ${ }^{5}$ \& \\ Maria Fernanda Tourinho Peres ${ }^{6}$
}

We examined the association of physical activity (PA) facilities and access to school with total PA and domain-specific PA in adolescents. We enrolled 2610 adolescents (mean: 14.9 years) from Sao Paulo city. The number and presence of sports courts, swimming pools, locker rooms, running/athletics tracks, entrance accessible for student cyclists, bike racks, speed limit signal around the school, and pedestrian crossing were assessed in each school. All participants responded to a questionnaire about frequency and duration of physical education classes, leisure time, and active commuting. Total PA was obtained by adding up all PA domains. Presence of three or more (OR: 1.62; 95\% Cl: 1.15 to 2.30) sports courts, swimming pool available in usable conditions (OR: $1.45 ; 95 \% \mathrm{Cl}: 1.01$ to 2.10 ), running/ athletics tracks (OR: $2.35 ; 95 \% \mathrm{Cl}: 1.07$ to 5.18 ), and bike racks (OR: $1.38 ; 95 \% \mathrm{Cl}: 1.07$ to 1.78 ) were positively associated with total PA. Number of sports courts, swimming pool available in usable conditions, speed limit signals around the school, and pedestrian crossings were positively associated with physical education classes. The bike racks, speed limit signs around the school, and pedestrian crossings were positively associated with active commuting. School environment was associated with increased PA. Our findings should be considered in future epidemiologic studies and for educational and health policy makers.

Several studies have shown the benefits of physical activity for adolescents' health ${ }^{1-3}$. Physical activity during childhood and adolescence is associated with adiposity status, cardiometabolic biomarkers, mental, psychological, behavioral conduct/pro-social behavior, cognition/academic achievement, and physical fitness in the short, mid- and long-term ${ }^{2}$. Despite these benefits, fewer than $20 \%$ of adolescents worldwide and only $29 \%$ of Brazilian children aged 11-17 years participate in sufficient physical activity ${ }^{4}$. For adolescents aged 5-17 years, the 2020 World Health Organization Guidelines for physical activity recommends an average of $60 \mathrm{~min} /$ day of moderate-to-vigorous physical activity ${ }^{1}$.

Promoting physical activity in adolescents living in megacities is challenging, particularly in low- and middleincome countries which have faced remarkable urbanization in the last decades. By 2030, the world is expected to have 41 megacities, and more than $90 \%$ of the future urban population growth will be in low- and middleincome countries ${ }^{5}$. Sao Paulo (Brazil) is the largest megacity in Latin America and one of the largest megacities in the world. With approximately 20.5 million inhabitants ${ }^{6}$, Sao Paulo is characterized by regions with extreme poverty, high occurrence of violence, heavy traffic, air and noise pollution, insecurity spread throughout the city. Moreover, similar to other megacities in low- and middle-income countries, Sao Paulo has faced a fast-paced an unplanned urban growth ${ }^{7,8}$. These changes in the city's urban environment are likely to impact physical activity ${ }^{9,10}$, as demonstrated by our previous study which showed that only $12.7 \%$ of adolescents from Sao Paulo engaged in sufficient physical activity ${ }^{9}$.

Physical activity is determined not solely by individual behavior and choices, but also by sociocultural and environmental factors such as school environments ${ }^{11,12}$. Factors that may affect adolescents' physical activity during school hours include physical, social, or institutional structures. These factors are in line with ecological models of behavior change in which an environment can influence health behaviors ${ }^{13,14}$.

\footnotetext{
${ }^{1}$ Escuela de Ciencias de la Actividad Física, el Deporte y la Salud, Universidad de Santiago de Chile (USACH), Las Sophoras 175, Estación Central, Santiago, Chile. ${ }^{2}$ Departamento de Medicina Preventiva, Escola Paulista de Medicina, Universidade Federal de São Paulo, São Paulo, Brazil. ${ }^{3}$ School of Arts, Sciences and Humanities, University of Sao Paulo, São Paulo, Brazil. ${ }^{4}$ Graduate Program in Nutrition in Public Health, Department of Nutrition, School of Public Health, University of Sao Paulo, São Paulo, SP, Brazil. ${ }^{5}$ School of Human Movement and Nutrition Sciences, The University of Queensland, Brisbane, Australia. ${ }^{6}$ Departamento de Medicina Preventiva, Faculdade de Medicina, Universidade de São Paulo, São Paulo, Brazil. ${ }^{\circledR}$ email: gerson.demoraes@usach.cl
} 
In addition, monetary aspects may affect the ability of schools to provide opportunities to encourage physical activity among adolescents within the school environment. There is a growing body of research into the influence of the school environment, particularly barriers and enablers, in adolescents' physical activity ${ }^{15,16}$. A review ${ }^{16}$ and a mixed-method review ${ }^{15}$ demonstrated that schools are more able to enhance adolescents' physical activity when they emphasize resource provision for physical activity within the school day, create a "culture" of physical activity, train teachers to support a positive climate for physical activity promotion, and ensure extracurricular physical activity opportunities for all adolescents. However, few studies have shown the association between facilities for physical activity in the school and access to school with total and domain-specific physical activity in adolescents living in megacities from low- to middle-income countries ${ }^{17}$.

Given adolescents are likely to spend a substantially amount of daily hours in the school, alteration of physical activity in youth should consider the school environment ${ }^{9,18,19}$. Furthermore, non-availability of, or nonaccessibility to activities at school have been reported as main barriers to physical activity involvement among adolescents $^{20,21}$. Therefore, physical activity facilities in schools and access to school are central reasons to be measured in the promotion of physical activity in adolescents ${ }^{21}$.

Studies on adolescents from the high-income countries found significant associations between physical activity facilities and total physical activity ${ }^{22-24}$. However, there are relatively few representative studies about these factors mega cities in low- to middle income countries, particularly in Latin America ${ }^{25}$. Furthermore, to analyze the associations between physical activity facilities and access to school may contribute to the physical activity opportunities of the Latin American adolescents. In this study, we examined the association of physical activity facilities and the access to school with total physical domain-specific physical activity in adolescents from Sao Paulo city, Brazil.

\section{Methods}

Sao Paulo project for the social development of children and adolescents. São Paulo para o desenvolvimento social de crianças e adolescentes (SP-PROSO-São Paulo Project for the Social Development of Children and Adolescents) is a cross-sectional study that included a representative sample of 9th grade students from public and private schools in Sao Paulo, ${ }^{9,26}$. Data collection was conducted between August and November 2017. The overarching SP-PROSO protocol was approved by the Ethics and Research Committee of the University of Sao Paulo School of Medicine (records no. 1.719.856) and the National Commission for Research Ethics (records no. 2.014.816). Written informed consent was obtained from a parent or legal guardian of all participants from the individual studies. All methods were carried out in accordance with relevant guidelines and regulations. Further details on SP-PROSO have been described elsewhere?.

A multi-stage sampling process was used to select participants of SP-PROSO. According to the school Census conducted in 2015, Sao Paulo had 175,854 ninth-grade students, who were enrolled across 2086 public (state and municipal) and private schools. Initially, 156 schools were randomly selected, of which 119 agreed to participate. Of the 61 private schools drawn, 26 refused to participate and 3 did not respond to our invitation and were excluded. Of the public schools, there was only one loss among the state schools and seven among the municipal schools. In each school, one class was selected and all students were eligible and invited to participle. Of 2816 eligible students, 2702 responded to a questionnaire. Our final analytical sample included 2610 participants with complete information on physical activity, which represented a final response rate of $93 \%$ (Fig. 1). Details on participant sampling, recruitment strategies, refused participants, and those who did not respond to our invitation have been published elsewhere ${ }^{9,26}$.

Physical activity assessment. Participants reported their physical activity levels by completing a selfreported questionnaire. This questionnaire has been used in the National Survey of School Health (2009, and $2019)^{27}$. The indicators of physical activity from questionnaire showed satisfactory relative validity compared with three 24-h recalls for $300 \mathrm{~min} /$ week (sensitivity: 78\%; specificity: 69\%; accuracy index: $73 \%$ ) and $150 \mathrm{~min} /$ week (sensitivity: $88 \%$; specificity: $49 \%$; accuracy index: $78 \%$ ) of adolescent's physical activity ${ }^{28}$.

The participants were instructed to report their weekly frequency and duration of physical activity in the domains of physical education classes, leisure physical activity, and active commuting (walking or cycling) to or from school during the past week.

These questions were asked separately for each domain of physical activity. We calculated total physical activity by adding the minutes per day ( $\mathrm{min} /$ day) of each domain of physical activity (physical education at school, leisure time physical activity, and active commuting). Total physical activity and leisure time of adolescents was categorized as $<60 \mathrm{~min} /$ day or as $\geq 60 \mathrm{~min} /$ day, according on the 2020 World Health Organization Recommendation for physical activity ${ }^{1}$. Physical education classes was categorized based on the number of classes offered per week in most Sao Paulo schools ${ }^{29}$ as $<2$ or $\geq 2$ week. Since only $2.1 \%$ of the students met physical activity guidelines thresholds for commuting in our sample and there are no specific guidelines for active commuting, we opt to categorize active commuting on weekly frequency, as none or $\geq 1$ week.

School-environment assessment. The school-environment was assessed using a questionnaire completed by a designated staff member, who observed each physical activity facility and access to school separately. Physical activity facilities and access to school considered were: number of sports courts (none to three or more; categorized as $\leq 1,2$ and $\geq 3$ ), availability of swimming pool (does not have one, it is not in usable conditions, in usable conditions; categorized as none and not fit for use, and in usable conditions), locker room (does not have one, it is not in usable conditions, in usable conditions; categorized as none and not fit for use, and in usable conditions), running/athletics tracks (does not have one, has one), entrance accessible for student cyclists (no, 


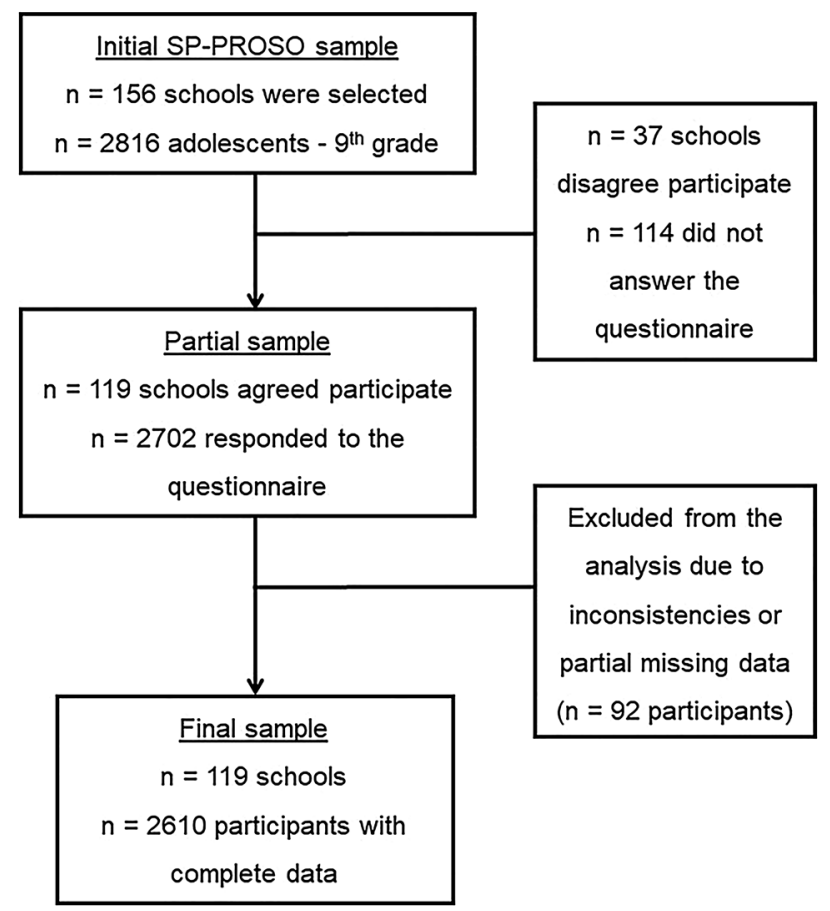

Figure 1. Flow chart of selection of SP-Proso participants.

yes), bike rack (no, yes), speed limit signal around the school (no, yes), and pedestrian crossing (no, yes). Type of school (municipal public, state public, and private) also was considered ${ }^{9,21,30}$.

We also generated a composite variable based on the "number of physical activity facilities" at the school by adding the number of physical activity facilities (yes $=1$; no $=0$ ) (sports courts, availability of swimming pool, locker room, running/athletics tracks, entrance accessible for student cyclists, bike racks, speed limit signal around the school, and pedestrian crossing. The variable ranged from zero (no facility available) to eight (five facilities evaluated were available and in usable conditions). The number of physical activity facilities was categorized as $\leq 1,2-4$, and $\geq 5$.

Sociodemographic variables. The socioeconomic level was assessed based on mother's education level (incomplete elementary, incomplete secondary, complete secondary or complete higher) and a series of enquiries that explored the possession of goods and the presence of a maid in the household. These questions have been used in the National School-Based Health Survey (Pesquisa Nacional de Saúde do Escolar-PeNSE). The PeNSE survey involved questions about the existence of goods in the home (the home where the adolescents actually lived). This questionnaire and method of evaluating socioeconomic level has been extensively used in Brazilian surveys ${ }^{9,30}$.

The socioeconomic level was designed through principal component analysis (PCA $)^{30}$. PCA was run adding to the model: maternal educational level, type of school, landline, cell phone, computer with internet access in the room, car, and number of bathrooms within the household. Details about the components of the PCA and the equation were published earlier ${ }^{9,30}$. Socioeconomic level was characterized as terciles of the total wealth scores, in which the first tercile (low) is the poorest group and the third tercile (high) is the wealthiest group.

Participants also self-reported their skin color/ethnicity [white, black, mixed, others (yellow, indigenous)] and mother's employment status (none, part-time, and full-time).

Statistical analysis. Descriptive statistics included frequency and proportions of adolescent characteristics by total physical activity level ( $<60 \mathrm{~min} /$ day vs $\geq 60 \mathrm{~min} /$ day) and school characteristics. We also calculated the proportion and its respective $95 \%$ confidence interval (95\% CI) of total and domain-specific physical activity (physical education classes, leisure time physical activity, and active commuting) according to school characteristics.

A multilevel logistic regression model with the number of enrolled students in the school as the first level and type of schools as the second level, were used to estimate the odds ratios (OR) and 95\% confidence intervals (95\% CI) for the associations of school environment with total physical activity and domain-specific physical activity, adjusted for sex, age (years), skin color/ethnicity, and mother's employment status. We performed unadjusted and adjusted models including physical activity facilities and access to school separately (number of sports courts, swimming pools, locker rooms, running/athletics tracks, accessible entrance for student cyclists, bike racks, speed limit signal around the school, pedestrian crossing, and number of physical activity facilities) for total physical activity and each domain of physical activity. 


\begin{tabular}{|c|c|c|c|}
\hline Variable & n (\%) & $<60 \mathrm{~min} /$ day & $\geq 60 \mathrm{~min} /$ day \\
\hline Total & 2610 & $2271(87.0)$ & $339(13.0)$ \\
\hline \multicolumn{4}{|l|}{ Sex } \\
\hline Boys & $1.363(52.2)$ & $1116(81.9)$ & $247(18.1)$ \\
\hline Girls & $1.247(47.8)$ & $1155(92.6)$ & $92(7.4)$ \\
\hline \multicolumn{4}{|l|}{ Skin color/ethnicity } \\
\hline White & $1.161(44.5)$ & $1001(86.2)$ & $160(13.8)$ \\
\hline Black & $323(12.4)$ & $289(89.5)$ & $34(10.5)$ \\
\hline Mixed & $955(36.6)$ & $825(86.4)$ & $130(13.6)$ \\
\hline Other & $171(6.5)$ & $148(86.5)$ & $23(13.5)$ \\
\hline \multicolumn{4}{|l|}{ Wealth scores } \\
\hline First tercile & $862(33.0)$ & $782(90.8)$ & $80(9.2)$ \\
\hline Second tercile & $859(32.9)$ & $748(87.1)$ & $111(12.9)$ \\
\hline Third tercile & $889(34.1)$ & $733(82.4)$ & $156(17.6)$ \\
\hline \multicolumn{4}{|c|}{ Mother's education level $^{*}$} \\
\hline Incomplete elementary & $331(16.5)$ & $285(86.1)$ & $46(13.9)$ \\
\hline Incomplete secondary & $287(14.3)$ & $256(89.2)$ & $31(10.9)$ \\
\hline Complete secondary & $698(34.9)$ & $605(86.7)$ & $93(13.3)$ \\
\hline Complete higher & $684(34.4)$ & $580(84.8)$ & $104(15.2)$ \\
\hline \multicolumn{4}{|c|}{ Mother's employment status } \\
\hline None & $969(37.1)$ & $904(93.3)$ & $65(6.7)$ \\
\hline Part-time & $769(29.5)$ & $679(88.3)$ & $90(11.7)$ \\
\hline Full-time & $872(33.4)$ & $750(86.0)$ & $122(14.0)$ \\
\hline
\end{tabular}

Table 1. Characteristics of adolescents by total physical activity level ( $<60 \mathrm{~min} /$ day vs $\geq 60 \mathrm{~min} /$ day). SP-PROSO, São Paulo, 2017. ${ }^{\star}$ The maternal education variable had substantial missing data $(\mathrm{n}=2000)$.

Statistical analyses were carried out using SPSS v.26 (SPSS Inc., IBM Corp., Armonk, New York, NY, USA). Given the exploratory nature of this study $95 \%$ CI were used to guide the interpretation of the associations ${ }^{31}$.

Ethics approval. The protocol was approved by the Ethics and Research Committee of the University of Sao Paulo School of Medicine (Comitê de Ética e Pesquisa da Faculdade de Medicina da Universidade de São Paulo, records no. 1.719.856) and the National Commission for Research Ethics (Comissão Nacional de Ética em Pesquisa [CONEP], records no. 2.014.816).

\section{Results}

The final sample size with complete data consisted of 2610 adolescents [52.2\% boys; mean age 14.9 (SD: 0.71 )]. The preponderance of the sample had white skin color/ethnicity (44.5\%), third tercile of wealth index (34.1\%), had mothers who completed secondary education (34.9\%) and whose mothers' employment status was unemployed (37.1\%) (Table 1 ).

The proportion of adolescents who did $\geq 60 \mathrm{~min} /$ day of total physical activity was $13 \%$, with a higher proportion in boys $(18.1 \%)$ than girls $(7.4 \%)$; those in the third tercile of wealth score $(17.6 \%)$ than in the first tercile of wealth score $(9.2 \%)$; those whose mothers completed higher education $(15.2 \%)$ than those whose mothers did not complete middle school (10.9\%); and those whose mothers had a full time job (14.0\%) than those whose mothers were unemployed (6.7\%) (Table 1$)$.

Most of the schools were municipal public (40.0\%) and had at least two sports courts (53.0\%); $92 \%$ of schools did not have swimming pools in usable condition, $74 \%$ did not have locker rooms in usable condition (73.9\%) and $98 \%$ did not have running/athletics tracks (98.3\%). Over half schools had accessible entrances for student cyclists, pedestrian crossings, and two or more physical activity facilities. Over $50 \%$ of schools did not have bike racks and speed limit signs around the school (Table 2).

In the multivariable model, three or more (OR: $1.62 ; 95 \% \mathrm{CI}: 1.15 ; 2.30$ ) sports courts, swimming pool available in usable conditions (OR: 1.45; 95\% CI: 1.01; 2.10), running/athletics tracks (OR: 2.35; 95\% CI: 1.07; 5.18), and have bike racks (OR: 1.38; 95\% CI: 1.07; 1.78) were positively associated with higher odds of the achievement of a total minimum recommended physical activity (here defined as $\geq 60 \mathrm{~min} /$ day) (Table 3 ).

The presence of two (OR: 1.28; 95\% CI: 1.07; 1.52) and three or more (OR: 1.34; 95\% CI: 1.03; 1.73) sports courts, swimming pool available in usable conditions (OR: 1.42; 95\% CI: 1.21; 1.67), speed limit signals around the school (OR: 1.29; 95\% CI: 1.09; 1.53), and pedestrian crossings (OR: 1.34; 95\% CI: 1.14; 1.58) positively associated with higher odds of the physical education classes (here defined as $\geq 2$ week) (Table 4).

We did not observe associations between any physical activity facilities and extracurricular sports activities in schools with leisure-time physical activity (here defined as $\geq 60 \mathrm{~min} /$ day) (Table 5). 


\begin{tabular}{|c|c|}
\hline Variable & n (\%) \\
\hline Type of school & 119 \\
\hline Municipal public & $48(40.0)$ \\
\hline State public & $38(32.2)$ \\
\hline Private & $33(27.8)$ \\
\hline \multicolumn{2}{|c|}{ Physical activity facilities in the school } \\
\hline \multicolumn{2}{|c|}{ Sports courts } \\
\hline$\leq 1$ & $42(36.5)$ \\
\hline 2 & $61(53.0)$ \\
\hline$\geq 3$ & $12(10.5)$ \\
\hline \multicolumn{2}{|l|}{ Swimming pool } \\
\hline None and not fit for use & $106(92.2)$ \\
\hline In usable conditions & $9(7.8)$ \\
\hline \multicolumn{2}{|l|}{ Locker room } \\
\hline None and not fit for use & $85(73.9)$ \\
\hline In usable conditions & $30(26.1)$ \\
\hline \multicolumn{2}{|l|}{ Running/athletics tracks } \\
\hline No & $113(98.3)$ \\
\hline Yes & $2(1.7)$ \\
\hline \multicolumn{2}{|c|}{ Access to school related to physical activity } \\
\hline \multicolumn{2}{|c|}{ Accessible entrance for student cyclists } \\
\hline No & $45(39.1)$ \\
\hline Yes & $70(60.9)$ \\
\hline \multicolumn{2}{|l|}{ Bike racks } \\
\hline No & $82(71.3)$ \\
\hline Yes & $33(28.7)$ \\
\hline \multicolumn{2}{|c|}{ Speed limit signal around the school } \\
\hline No & $75(65.2)$ \\
\hline Yes & $40(34.8)$ \\
\hline \multicolumn{2}{|l|}{ Pedestrian crossings } \\
\hline No & $51(44.3)$ \\
\hline Yes & $64(55.6)$ \\
\hline \multicolumn{2}{|c|}{ Number of physical activity facilities } \\
\hline$\leq 1$ & $24(20.9)$ \\
\hline $2-4$ & $48(41.7)$ \\
\hline$\geq 5$ & $43(37.4)$ \\
\hline
\end{tabular}

Table 2. Characteristics, physical activity facilities and access to school environment in the selected schools. SP-PROSO, São Paulo, 2017.

The bike racks (OR: 1.27; 95\% CI: 1.07; 1.51), speed limit signs around the school (OR: 1.42; 95\% CI: 1.19; 1.68 ), and pedestrian crossings (OR: $1.31 ; 95 \%$ CI: $1.11 ; 1.54$ ) were positively associated with higher odds of the active commuting (here defined as $\geq 1$ week) (Table 6).

\section{Discussion}

This cross-sectional study examined the associations of school environment with total physical activity and domain-specific physical activity in adolescents from the largest city in Latin America, Sao Paulo. We found that higher number of sports courts $(\geq 3)$, swimming pool available in usable conditions, running/athletics tracks, and bike racks were positively associated with total physical activity ( $\geq 60 \mathrm{~min} /$ day). We found specific associations between school characteristics and domains of physical activity in adolescents. Our study provides highlight the importance of school environment to promote physical activity for adolescents.

We found a positive association between the presence of two or more sports courts, swimming pools available in usable conditions, speed limit signs around the school, and pedestrian crossings and participation in physical education classes. Previous studies have shown that adolescents spent more time in physical education classes in schools that had sports court availability ${ }^{21,32}$. A systematic review concluded that students attending schools with the higher number of physical environment features may have increased physical activity (compared to lower number of facilities) ${ }^{33}$. Therefore, improving the amount, variety and condition of the facilities in the school environment may be relevant strategies to increase physical activity at school and enhance the participation in physical education classes. The present results corroborate previous studies that have attributed a significant association of the school context variability on physical activity. It is likely that, in the case of the 


\begin{tabular}{|c|c|c|c|c|c|c|}
\hline \multirow[b]{3}{*}{ Variable } & \multicolumn{6}{|c|}{ Total physical activity ( $\geq 60 \mathrm{~min} /$ day) } \\
\hline & \multicolumn{2}{|c|}{ Prevalence } & \multicolumn{2}{|c|}{\begin{tabular}{|l|} 
Unadjusted \\
model $^{*}$
\end{tabular}} & \multicolumn{2}{|c|}{ Adjusted model ${ }^{\star *}$} \\
\hline & $\%$ & $95 \% \mathrm{CI}$ & OR & $95 \% \mathrm{CI}$ & OR & 95\% CI \\
\hline \multicolumn{7}{|l|}{ Sports court } \\
\hline$\leq 1$ & 12.1 & $10.1 ; 14.1$ & Ref. & & Ref. & \\
\hline 2 & 12.3 & $10.6 ; 14.1$ & 1.02 & $0.79 ; 1.31$ & 1.01 & $0.78 ; 1.31$ \\
\hline$\geq 3$ & 17.7 & $14.0 ; 22.1$ & 1.56 & $1.11 ; 2.18$ & 1.62 & $1.15 ; 2.30$ \\
\hline \multicolumn{7}{|l|}{ Swimming pool } \\
\hline None and not fit for use & 12.5 & $11.2 ; 13.9$ & Ref. & & Ref. & \\
\hline In usable conditions & 16.9 & $12.7 ; 21.5$ & 1.42 & $1.01 ; 2.01$ & 1.45 & $1.01 ; 2.10$ \\
\hline \multicolumn{7}{|l|}{ Locker room } \\
\hline None and not fit for use & 12.1 & $10.0 ; 14.1$ & Ref. & & Ref. & \\
\hline In usable conditions & 14.5 & $12.0 ; 17.0$ & 1.18 & $0.89 ; 1.55$ & 1.15 & $0.86 ; 1.53$ \\
\hline \multicolumn{7}{|c|}{ Running/athletics tracks } \\
\hline No & 12.8 & $11.6 ; 14.1$ & Ref. & & Ref. & \\
\hline Yes & 25.0 & $11.1 ; 38.9$ & 2.27 & $1.06 ; 4.87$ & 2.35 & $1.07 ; 5.18$ \\
\hline \multicolumn{7}{|c|}{ Accessible entrance for student cyclists } \\
\hline No & 12.9 & $10.9 ; 15.3$ & Ref. & & Ref. & \\
\hline Yes & 13.1 & $11.2 ; 14.5$ & 1.02 & $0.81 ; 1.28$ & 1.04 & $0.82 ; 1.32$ \\
\hline \multicolumn{7}{|l|}{ Bike racks } \\
\hline No & 11.7 & $10.2 ; 13.1$ & Ref. & & Ref. & \\
\hline Yes & 15.7 & $13.2 ; 18.3$ & 1.40 & $1.11 ; 1.77$ & 1.38 & $1.07 ; 1.78$ \\
\hline \multicolumn{7}{|c|}{ Speed limit signs around the school } \\
\hline No & 12.6 & $10.9 ; 14.1$ & Ref. & & Ref. & \\
\hline Yes & 13.8 & $11.5 ; 15.8$ & 1.11 & $0.87 ; 1.41$ & 1.12 & $0.85 ; 1.46$ \\
\hline \multicolumn{7}{|l|}{ Pedestrian crossings } \\
\hline No & 12.3 & $10.4 ; 14.2$ & Ref. & & Ref. & \\
\hline Yes & 13.5 & $11.7 ; 15.3$ & 1.13 & $0.88 ; 1.40$ & 1.13 & $0.89 ; 1.45$ \\
\hline \multicolumn{7}{|c|}{ Number of physical activity facilities } \\
\hline$\leq 1$ & 6.8 & $3.1 ; 13.7$ & Ref. & & Ref. & \\
\hline $2-4$ & 13.2 & $10.8 ; 15.4$ & 2.06 & $0.81 ; 5.22$ & 2.03 & $0.79 ; 5.20$ \\
\hline$\geq 5$ & 13.1 & $11.5 ; 14.7$ & 2.04 & $0.82 ; 5.14$ & 2.01 & $0.79 ; 5.08$ \\
\hline
\end{tabular}

Table 3. Association between school environment and total physical activity in adolescents. Values in bold indicate significant associations; 95\% CI 95\% confidence intervals, OR odds ratio. ${ }^{\star}$ Number of adolescents enrolled in the school as first level and type of school as second level. ${ }^{*}$ Number of adolescents enrolled in the school as first level, type of school as second level, adjusted by sex, age (years), skin color/ethnicity, and mother's employment status.

present study, this fact was due to the sampling randomness in each school, as well as the possible similarity regarding the infrastructure.

We not found significant associations between any physical activity facilities and extracurricular sports activities in schools with leisure time physical activity ( $\geq 60 \mathrm{~min} /$ day). On the other hand, Rezende et al. ${ }^{21}$ used data collected for PeNSE (Pesquisa Nacional de Saúde do Escolar-National Survey of School Health) showed positive associations between number of sports court $(\geq 2)$, the presence of running/athletics track, and swimming pool available in usable condition with leisure-time physical activity in adolescents from Brazil. The difference in these findings may be due to the different cut-offs. The authors concluded that school context has important potential to increase the engagement of adolescents in physical activity. Therefore, school environment has a fundamental role in allowing adolescents, who spend part of their day in school, to have a more active lifestyle ${ }^{21}$. Furthermore, there is still no physical activity guidelines for each domain of physical activity ${ }^{1}$. Of note, leisure time physical activity contribute to $41.3 \%$ of total physical activity in adolescents from Sao Paulo ${ }^{9}$ Therefore, physical activity interventions, especially recreational activities, are important to increase the total physical activity in adolescent from Sao Paulo.

Our study also showed an association between school environment (bike racks, speed limit signs around the school, and pedestrian crossings) and active commuting ( $\geq 1$ week). Active commuting is an essential source of physical activity and has been associated with higher physical activity levels in adolescents ${ }^{9}$. Safety, social support for commuting and the built environment have been reported to be important determinants of active commuting in adolescents from high-income countries ${ }^{14}$. Furthermore, density of exercise facilities and urbanization (i.e., urban versus rural residences) are positively associated with physical activity ${ }^{13}$. Distance from home to school is the most common barrier to active commuting to school, especially because it is the primary factor in the 


\begin{tabular}{|c|c|c|c|c|c|c|}
\hline \multirow[b]{3}{*}{ Variable } & \multicolumn{6}{|c|}{ Physical education classes ( $\geq 2$ week) } \\
\hline & \multicolumn{2}{|c|}{ Prevalence } & \multicolumn{2}{|c|}{$\begin{array}{l}\text { Unadjusted } \\
\text { model }^{*}\end{array}$} & \multicolumn{2}{|c|}{ Adjusted model ${ }^{\star \star}$} \\
\hline & $\%$ & $95 \% \mathrm{CI}$ & OR & $95 \% \mathrm{CI}$ & OR & 95\% CI \\
\hline \multicolumn{7}{|l|}{ Sports court } \\
\hline$\leq 1$ & 46.7 & $43.4 ; 49.9$ & Ref. & & Ref. & \\
\hline 2 & 53.0 & $50.3 ; 55.9$ & 1.28 & $1.08 ; 1.52$ & 1.28 & $1.07 ; 1.52$ \\
\hline$\geq 3$ & 54.2 & $48.8 ; 59.6$ & 1.35 & $1.05 ; 1.73$ & 1.34 & $1.03 ; 1.73$ \\
\hline \multicolumn{7}{|l|}{ Swimming pool } \\
\hline None and not fit for use & 49.5 & $47.5 ; 51.7$ & Ref. & & Ref. & \\
\hline In usable conditions & 63.5 & $57.5 ; 69.0$ & 1.77 & $1.35 ; 2.32$ & 1.42 & $1.21 ; 1.67$ \\
\hline \multicolumn{7}{|l|}{ Locker room } \\
\hline None and not fit for use & 52.2 & $49.0 ; 55.4$ & Ref. & & Ref. & \\
\hline In usable conditions & 50.5 & $47.1 ; 54.4$ & 0.89 & $0.81 ; 1.19$ & 0.97 & $0.80 ; 1.18$ \\
\hline \multicolumn{7}{|l|}{ Running/athletics tracks } \\
\hline No & 50.7 & $48.8 ; 52.8$ & Ref. & & Ref. & \\
\hline Yes & 62.5 & $43.8 ; 78.1$ & 1.61 & $0.78 ; 3.32$ & 1.64 & $0.80 ; 3.39$ \\
\hline \multicolumn{7}{|c|}{ Accessible entrance for student cyclists } \\
\hline No & 48.6 & $45.4 ; 54.6$ & Ref. & & Ref. & \\
\hline Yes & 52.4 & $49.7 ; 55.0$ & 1.16 & $0.99 ; 1.36$ & 1.17 & $0.99 ; 1.37$ \\
\hline \multicolumn{7}{|l|}{ Bike racks } \\
\hline No & 49.4 & $46.9 ; 51.7$ & Ref. & & Ref. & \\
\hline Yes & 54.0 & $50.3 ; 57.4$ & 1.20 & $1.01 ; 1.42$ & 1.16 & $0.98 ; 1.38$ \\
\hline \multicolumn{7}{|c|}{ Speed limit signs around the school } \\
\hline No & 48.1 & $45.7 ; 50.5$ & Ref. & & Ref. & \\
\hline Yes & 54.5 & $51.2 ; 57.5$ & 1.29 & $1.09 ; 1.52$ & 1.29 & $1.09 ; 1.53$ \\
\hline \multicolumn{7}{|l|}{ Pedestrian crossings } \\
\hline No & 46.6 & $43.6 ; 49.3$ & Ref. & & Ref. & \\
\hline Yes & 54.0 & $51.5 ; 56.8$ & 1.34 & $1.14 ; 1.57$ & 1.34 & $1.14 ; 1.58$ \\
\hline \multicolumn{7}{|c|}{ Number of physical activity facilities } \\
\hline$\leq 1$ & 46.4 & $34.8 ; 58.0$ & Ref. & & Ref. & \\
\hline $2-4$ & 49.2 & $45.9 ; 52.7$ & 1.12 & $0.68 ; 1.83$ & 1.21 & $0.73 ; 2.01$ \\
\hline$\geq 5$ & 51.9 & $49.6 ; 54.3$ & 1.24 & $0.77 ; 2.02$ & 1.33 & $0.81 ; 2.18$ \\
\hline
\end{tabular}

Table 4. Association between school characteristics and participation in physical education classes in adolescents. Values in bold indicate significant associations; 95\% CI 95\% confidence intervals, OR odds ratio. ${ }^{\star}$ Number of adolescents enrolled in the school as first level and type of school as second level. ${ }^{*}$ Number of adolescents enrolled in the school as first level, type of school as second level, adjusted by sex, age (years), skin color/ethnicity, and mother's employment status.

parents' decision-making process for or against allowing their child to walk or cycle to school ${ }^{34}$. In addition, it may not be feasible to walk or cycle to school if the distance is too far in medium-sized towns possibly because of higher traffic density ${ }^{35}$. Sao Paulo is among the 10 most urbanized, highly disorganized cities, with heavy traffic, air and noise pollution, rising crime rates and high-income inequality ${ }^{8}$. Future research should address the physical and social environmental determinants of active commuting such as safety, presence of sidewalks and bicycle lanes, and availability of infrastructure to verify this hypothesis in adolescents from low-income to middle income countries.

Our results are also consistent with previous studies showing a positive association between the amount of school facilities and adolescent physical activity ${ }^{36,37}$. A significant number of physical activity facilities must be implemented in schools, as this might help to offer a diversity of opportunities for physical activity ${ }^{38}$. Possibly, more recreational activities and spaces with equipment and/or 'obstacles (natural or built), which stimulate the increase of the total physical activity levels ${ }^{39}$. The proposal for a diverse infrastructure and open school would enhance the capability of the school to promote societal knowledge related to body culture and understanding of concepts such as leisure goals, expression of feelings, affections and emotions, and opportunities to promote, restore and maintain health, one of the aims of the Programa Saúde na Escola (Health in Schools Program), in Brazil $^{40}$. 


\begin{tabular}{|c|c|c|c|c|c|c|}
\hline \multirow[b]{3}{*}{ Variable } & \multicolumn{6}{|c|}{ Leisure time physical activity ( $\geq 60 \mathrm{~min} /$ day) } \\
\hline & \multicolumn{2}{|c|}{ Prevalence } & \multicolumn{2}{|c|}{\begin{tabular}{|l|} 
Unadjusted \\
model $^{*}$
\end{tabular}} & \multicolumn{2}{|c|}{$\begin{array}{l}\text { Adjusted } \\
\text { model }^{\star *}\end{array}$} \\
\hline & $\%$ & $95 \% \mathrm{CI}$ & OR & $95 \% \mathrm{CI}$ & OR & 95\% CI \\
\hline \multicolumn{7}{|l|}{ Sports court } \\
\hline$\leq 1$ & 9.0 & $6.6 ; 11.4$ & Ref. & & Ref. & \\
\hline 2 & 8.5 & $6.5 ; 10.4$ & 0.93 & $0.64 ; 1.36$ & 0.96 & $0.66 ; 1.41$ \\
\hline$\geq 3$ & 7.7 & $4.5 ; 11.3$ & 0.84 & $0.47 ; 1.48$ & 0.90 & $0.51 ; 1.61$ \\
\hline \multicolumn{7}{|l|}{ Swimming pool } \\
\hline None and not fit for use & 8.5 & $7.1 ; 9.9$ & Ref. & & Ref. & \\
\hline In usable conditions & 9.8 & $5.5 ; 14.7$ & 1.17 & $0.68 ; 2.02$ & 1.26 & $0.72 ; 2.19$ \\
\hline \multicolumn{7}{|l|}{ Locker room } \\
\hline None and not fit for use & 10.0 & $7.9 ; 12.8$ & Ref. & & Ref. & \\
\hline In usable conditions & 7.1 & $4.9 ; 9.4$ & 0.82 & $0.52 ; 1.28$ & 0.83 & $0.52 ; 1.31$ \\
\hline \multicolumn{7}{|l|}{ Running/athletics tracks } \\
\hline No & 8.6 & $7.2 ; 10.0$ & Ref. & & Ref. & \\
\hline Yes & 9.5 & $3.9 ; 15.1$ & 1.12 & $0.25 ; 4.90$ & 1.11 & $0.25 ; 4.88$ \\
\hline \multicolumn{7}{|c|}{ Accessible entrance for student cyclists } \\
\hline No & 8.1 & $6.4 ; 9.9$ & Ref. & & Ref. & \\
\hline Yes & 9.3 & $7.1 ; 11.6$ & 1.15 & $0.81 ; 1.64$ & 1.14 & $0.80 ; 1.63$ \\
\hline \multicolumn{7}{|l|}{ Bike racks } \\
\hline No & 7.8 & $6.0 ; 9.5$ & Ref. & & Ref. & \\
\hline Yes & 10.2 & $7.8 ; 12.7$ & 1.34 & $0.94 ; 1.92$ & 1.35 & $0.94 ; 1.94$ \\
\hline \multicolumn{7}{|c|}{ Speed limit signs around the school } \\
\hline No & 9.3 & $7.5 ; 11.2$ & Ref. & & Ref. & \\
\hline Yes & 7.5 & $5.6 ; 9.9$ & 0.78 & $0.53 ; 1.15$ & 0.79 & $0.54 ; 1.17$ \\
\hline \multicolumn{7}{|l|}{ Pedestrian crossings } \\
\hline No & 8.5 & $6.4 ; 10.6$ & Ref. & & Ref. & \\
\hline Yes & 8.7 & $6.8 ; 10.7$ & 1.01 & $0.71 ; 1.45$ & 1.06 & $0.74 ; 1.52$ \\
\hline \multicolumn{7}{|c|}{ Number of physical activity facilities } \\
\hline$\leq 1$ & 4.3 & $0.8 ; 7.8$ & Ref. & & Ref. & \\
\hline $2-4$ & 8.8 & $6.5 ; 11.3$ & 2.17 & $0.51 ; 9.23$ & 2.11 & $0.49 ; 9.03$ \\
\hline$\geq 5$ & 8.7 & $7.0 ; 10.6$ & 2.13 & $0.51 ; 8.95$ & 2.15 & $0.51 ; 9.06$ \\
\hline
\end{tabular}

Table 5. Association between school characteristics and leisure time physical activity in adolescents. $95 \%$ CI 95\% confidence intervals, OR odds ratio. ${ }^{*}$ Number of adolescents enrolled in the school as first level and type of school as second level. ${ }^{\star \star}$ Number of adolescents enrolled in the school as first level, type of school as second level, adjusted by sex, age (years), skin color/ethnicity, and mother's employment status.

Our study included a large representative sample of adolescents from the city of Sao Paulo to examine the association between school environment and physical activity. However, our findings should be interpreted in the light of some limitations. First, the cross-sectional associations must be interpreted cautiously, as they may not be appropriate for causal inference. Second, SP-PROSO study did not include adolescents of all ages and the results may not applicable to all ages. Third, physical activity information was collected through a self-reported questionnaire and therefore measurement error probably occurred. However, this physical activity questionnaire has shown a high relative ${ }^{28}$. The variable of mothers' education level has considerable missing data. Adolescents with missing maternal education data showed similar physical activity pattern ${ }^{9}$.

\section{Conclusions}

We found that schools with a higher number of physical activity facilities had higher odds of adolescents reaching the physical activity guidelines. Physical activity facilities were differentially associated with domain-specific physical activity, which can be useful to inform the development of future physical activity programs. The school environment may have an important role in allowing adolescents, who spend part of their day in school, to have a more active lifestyle. Prospective studies of school characteristics and physical activity are needed, as well as evidence from intervention studies in order to advance our understanding of these relationships and better inform educational and public health policy, programs and decision-makers. 


\begin{tabular}{|c|c|c|c|c|c|c|}
\hline \multirow[b]{3}{*}{ Variable } & \multicolumn{6}{|c|}{ Active commuting ( $\geq 1$ week) } \\
\hline & \multicolumn{2}{|c|}{ Prevalence } & \multicolumn{2}{|c|}{$\begin{array}{l}\text { Unadjusted } \\
\text { model }^{*}\end{array}$} & \multicolumn{2}{|c|}{ Adjusted model ${ }^{\star x}$} \\
\hline & $\%$ & $95 \% \mathrm{CI}$ & OR & $95 \% \mathrm{CI}$ & OR & $95 \% \mathrm{CI}$ \\
\hline \multicolumn{7}{|l|}{ Sports court } \\
\hline$\leq 1$ & 62.8 & $59.7 ; 65.9$ & Ref. & & Ref. & \\
\hline 2 & 58.6 & $55.9 ; 61.4$ & 0.84 & $0.64 ; 1.04$ & 0.81 & $0.60 ; 1.02$ \\
\hline$\geq 3$ & 55.2 & $50.1 ; 60.9$ & 0.73 & $0.40 ; 1.03$ & 0.72 & $0.42 ; 1.03$ \\
\hline \multicolumn{7}{|l|}{ Swimming pool } \\
\hline None and not fit for use & 60.2 & $58.3 ; 62.3$ & Ref. & & Ref. & \\
\hline In usable conditions & 54.5 & $48.6 ; 60.5$ & 0.79 & $0.61 ; 1.02$ & 0.79 & $0.60 ; 1.03$ \\
\hline \multicolumn{7}{|l|}{ Locker room } \\
\hline None and not fit for use & 58.9 & $55.4 ; 62.1$ & Ref. & & Ref. & \\
\hline In usable conditions & 56.6 & $53.4 ; 59.5$ & 0.84 & $0.69 ; 1.01$ & 0.85 & $0.70 ; 1.04$ \\
\hline \multicolumn{7}{|l|}{ Running/athletics tracks } \\
\hline No & 59.7 & $57.8 ; 61.6$ & Ref. & & Ref. & \\
\hline Yes & 60.6 & $42.4 ; 75.8$ & 1.04 & $0.51 ; 2.10$ & 1.04 & $0.51 ; 2.11$ \\
\hline \multicolumn{7}{|c|}{ Accessible entrance for student cyclists } \\
\hline No & 58.9 & $55.9 ; 61.8$ & Ref. & & Ref. & \\
\hline Yes & 60.2 & $57.7 ; 62.7$ & 1.05 & $0.89 ; 1.23$ & 1.06 & $0.89 ; 1.25$ \\
\hline \multicolumn{7}{|l|}{ Bike racks } \\
\hline No & 56.2 & $52.7 ; 59.9$ & Ref. & & Ref. & \\
\hline Yes & 61.3 & $59.2 ; 63.6$ & 1.23 & $1.05 ; 1.45$ & 1.27 & $1.07 ; 1.51$ \\
\hline \multicolumn{7}{|c|}{ Speed limit signs around the school } \\
\hline No & 54.7 & $51.5 ; 58.0$ & Ref. & & Ref. & \\
\hline Yes & 62.4 & $60.0 ; 65.0$ & 1.37 & $1.16 ; 1.62$ & 1.42 & $1.19 ; 1.68$ \\
\hline \multicolumn{7}{|l|}{ Pedestrian crossings } \\
\hline No & 57.2 & $54.7 ; 60.0$ & Ref. & & Ref. & \\
\hline Yes & 63.0 & $60.1 ; 66.1$ & 1.27 & $1.08 ; 1.49$ & 1.31 & $1.11 ; 1.54$ \\
\hline \multicolumn{7}{|c|}{ Number of physical activity facilities } \\
\hline$\leq 1$ & 64.3 & $52.9 ; 75.7$ & Ref. & & Ref. & \\
\hline $2-4$ & 61.5 & $58.2 ; 64.8$ & 0.88 & $0.53 ; 1.47$ & 0.84 & $0.50 ; 1.42$ \\
\hline$\geq 5$ & 58.5 & $56.1 ; 60.6$ & 0.78 & $0.47 ; 1.29$ & 0.72 & $0.43 ; 1.21$ \\
\hline
\end{tabular}

Table 6. Association between school characteristics and active commuting to/from school in adolescents. Values in bold indicate significant associations; 95\% CI 95\% confidence intervals, OR odds ratio. ${ }^{\star}$ Number of adolescents enrolled in the school as first level and type of school as second level. ${ }^{*}$ Number of adolescents enrolled in the school as first level, type of school as second level, adjusted by sex, age (years), skin color/ ethnicity, and mother's employment status.

\section{Data availability}

Data are available upon reasonable request from the corresponding author.

Received: 30 March 2021; Accepted: 23 August 2021

Published online: 13 September 2021

\section{References}

1. Bull, F. C. et al. World Health Organization 2020 guidelines on physical activity and sedentary behaviour. Br. J. Sports Med. 54, 1451-1462. https://doi.org/10.1136/bjsports-2020-102955 (2020).

2. Poitras, V. J. et al. Systematic review of the relationships between objectively measured physical activity and health indicators in school-aged children and youth. Appl. Physiol. Nutr. Metab. 41, S197-239. https://doi.org/10.1139/apnm-2015-0663 (2016).

3. McMahon, E. M. et al. Physical activity in European adolescents and associations with anxiety, depression and well-being. Eur. Child Adolesc. Psychiatry 26, 111-122. https://doi.org/10.1007/s00787-016-0875-9 (2017).

4. Guthold, R., Stevens, G. A., Riley, L. M. \& Bull, F. C. Global trends in insufficient physical activity among adolescents: A pooled analysis of 298 population-based surveys with 1.6 million participants. Lancet Child Adolesc. Health 4, 23-35. https://doi.org/10. 1016/S2352-4642(19)30323-2 (2020)

5. Division UNDP. World Urbanization Prospects: The 2014 Revision, 1-514 (2015).

6. Demographia World Urban Areas: 15th Annual Edition: 201904. Demographia (2019).

7. Peres, M. F. T., Cardia, N., Mesquita Neto, P., Santos, P. C. \& Adorno, S. Homicidios, desenvolvimento socioeconomico e violencia policial no Municipio de Sao Paulo, Brasil. Rev. Panam. Salud Publica 23(4), 268-276 (2008).

8. Greene, J. \& Guanais, F. An examination of socioeconomic equity in health experiences in six Latin American and Caribbean countries. Rev. Panam. Salud Publica 42, e127. https://doi.org/10.26633/RPSP.2018.127 (2018). 
9. Ferrari, G., Rezende, L. F. M., Wagner, G. A., Florindo, A. A. \& Peres, M. F. T. Physical activity patterns in a representative sample of adolescents from the largest city in Latin America: A cross-sectional study in Sao Paulo. BMJ Open 10, e037290. https://doi. org/10.1136/bmjopen-2020-037290 (2020).

10. Landin, R. \& Giatti, L. L. The climate change policy of the city of Sao Paulo, Brazil: Reflexivity and permeability of the health sector. Cien Saude Colet 19, 4149-4156. https://doi.org/10.1590/1413-812320141910.08972014 (2014).

11. Bauman, A. E., Sallis, J. F., Dzewaltowski, D. A. \& Owen, N. Toward a better understanding of the influences on physical activity: The role of determinants, correlates, causal variables, mediators, moderators, and confounders. Am. J. Prev. Med. 23, 5-14 (2002).

12. Sallis, J. F. et al. An ecological approach to creating active living communities. Annu. Rev. Public Health 27, 297-322. https://doi. org/10.1146/annurev.publhealth.27.021405.102100 (2006).

13. Bauman, A. E. et al. Correlates of physical activity: Why are some people physically active and others not?. Lancet 380, $258-271$. https://doi.org/10.1016/S0140-6736(12)60735-1 (2012).

14. Loh, V. H. Y. et al. Built environment and physical activity among adolescents: The moderating effects of neighborhood safety and social support. Int. J. Behav. Nutr. Phys. Act. 16, 132. https://doi.org/10.1186/s12966-019-0898-y (2019).

15. Morton, K. L., Atkin, A. J., Corder, K., Suhrcke, M. \& van Sluijs, E. M. The school environment and adolescent physical activity and sedentary behaviour: A mixed-studies systematic review. Obes. Rev. 17, 142-158. https://doi.org/10.1111/obr.12352 (2016).

16. Langford, R. et al. The World Health Organization's Health Promoting Schools framework: A Cochrane systematic review and meta-analysis. BMC Public Health 15, 130. https://doi.org/10.1186/s12889-015-1360-y (2015).

17. Elshahat, S., O’Rorke, M. \& Adlakha, D. Built environment correlates of physical activity in low- and middle-income countries: A systematic review. PLoS One 15, e0230454. https://doi.org/10.1371/journal.pone.0230454 (2020).

18. Ferrari, G. L. et al. Correlates of moderate-to-vigorous physical activity in Brazilian children. J. Phys. Act. Health 13, 1132-1145. https://doi.org/10.1123/jpah.2015-0666 (2016).

19. Silva, D. A. S. et al. Physical education classes, physical activity, and sedentary behavior in children. Med. Sci. Sports Exerc. 50, 995-1004. https://doi.org/10.1249/MSS.0000000000001524 (2018).

20. Eime, R. M., Harvey, J. T., Charity, M. J. \& Nelson, R. Demographic characteristics and type/frequency of physical activity participation in a large sample of 21,603 Australian people. BMC Public Health 18, 692. https://doi.org/10.1186/s12889-018-5608-1 (2018).

21. de Rezende, L. F. et al. The role of school environment in physical activity among brazilian adolescents. PLoS One 10, e0131342. https://doi.org/10.1371/journal.pone.0131342 (2015).

22. Gordon-Larsen, P., Nelson, M. C., Page, P. \& Popkin, B. M. Inequality in the built environment underlies key health disparities in physical activity and obesity. Pediatrics 117, 417-424. https://doi.org/10.1542/peds.2005-0058 (2006).

23. Hood, N. E., Colabianchi, N., Terry-McElrath, Y. M., O’Malley, P. M. \& Johnston, L. D. Physical activity breaks and facilities in US secondary schools. J. Sch. Health 84, 697-705. https://doi.org/10.1111/josh.12206 (2014).

24. Haapala, H. L. et al. Adolescents' physical activity at recess and actions to promote a physically active school day in four Finnish schools. Health Educ. Res. 29, 840-852. https://doi.org/10.1093/her/cyu030 (2014).

25. Figueiredo, T. K. F. et al. Changes in total physical activity, leisure and commuting in the largest city in Latin America, 2003-2015. Rev. Bras. Epidemiol. 24, e210030. https://doi.org/10.1590/1980-549720210030 (2021).

26. Peres, M. et al. Violência, bullying e repercussões na saúde: Resultados do projeto São Paulo para o desenvolvimento social de crianças e adolescentes (SP-PROSO), 1-154 (Departamento de Medicina Preventiva/FMUSP, 2018).

27. Instituto Brasileiro de Geografia e Estatística. Pesquisa Nacional de Saúde Escolar (IBGE, 2013).

28. Tavares, L. F. et al. Validity of indicators on physical activity and sedentary behavior from the Brazilian National School-Based Health Survey among adolescents in Rio de Janeiro, Brazil. Cad Saude Publica 30, 1861-1874. https://doi.org/10.1590/0102-311x0 0151913 (2014).

29. São Paulo (Estado) Secretaria da Educação. Currículo do Estado de São Paulo: Linguagens, códigos e suas tecnologias/Secretaria da Educação; coordenação geral, Maria Inês Fini; coordenação de área, Alice Vieira. 2. ed. (2011).

30. Barros, A. J. \& Victora, C. G. A nationwide wealth score based on the 2000 Brazilian demographic census. Rev. Saude Publica 39, 523-529. https://doi.org/10.1590/s0034-89102005000400002 (2005).

31. Lee, S. et al. Examining Trends and Averages Using Combined Cross-Sectional Survey Data from Multiple Years. CHIS Methodology Paper (2007).

32. Coledam, D. H., Ferraiol, P. F., Pires Junior, R., dos-Santos, J. W. \& Oliveira, A. R. Factors associated with participation in sports and physical education among students from Londrina, Parana State, Brazil. Cad. Saude Publica 30, 533-545. https://doi.org/10. 1590/0102-311x00087413 (2014).

33. Zhou, Y. \& Wang, L. Correlates of physical activity of students in secondary school physical education: A systematic review of literature. Biomed. Res. Int. 2019, 4563484. https://doi.org/10.1155/2019/4563484 (2019).

34. Rodriguez-Rodriguez, F. et al. Influence of distance, area, and cultural context in active commuting: Continental and insular children. PLoS One 14, e0213159. https://doi.org/10.1371/journal.pone.0213159 (2019).

35. Nelson, N. M., Foley, E., O'Gorman, D. J., Moyna, N. M. \& Woods, C. B. Active commuting to school: How far is too far?. Int. J. Behav. Nutr. Phys. Act. 5, 1. https://doi.org/10.1186/1479-5868-5-1 (2008).

36. Haug, E., Torsheim, T., Sallis, J. F. \& Samdal, O. The characteristics of the outdoor school environment associated with physical activity. Health Educ. Res. 25, 248-256. https://doi.org/10.1093/her/cyn050 (2010).

37. Fein, A. J., Plotnikoff, R. C., Wild, T. C. \& Spence, J. C. Perceived environment and physical activity in youth. Int. J. Behav. Med. 11, 135-142. https://doi.org/10.1207/s15327558ijbm1103_2 (2004).

38. Van Dyke, M. E., Cheung, P. C., Franks, P. \& Gazmararian, J. A. Socioeconomic and racial/ethnic disparities in physical activity environments in Georgia elementary schools. Am. J. Health Promot. 32, 453-463. https://doi.org/10.1177/0890117117717016 (2018).

39. Mendonca, G., Cheng, L. A. \& Farias Junior, J. C. Standards of physical activity practices in adolescents in a city of Northeastern Brazil. Cien. Saude Colet. 23, 2443-2451. https://doi.org/10.1590/1413-81232018237.21782016 (2018).

40. Brasil. Ministério da Educação. Programa Saúde na Escola 2014. http://portal.mec.gov.br/programa-saude-da-escola. Accessed 16 December 2020.

\section{Acknowledgements}

We would like to thank the adolescents participating in the SP-PROSO.

\section{Author contributions}

G.F. and L.F.M.R. had full access to all of the data in the study and take responsibility for the integrity of the data and the accuracy of the data analysis. The corresponding author had final responsibility for the decision to submit for publication. M.F.T.P. was the principal investigator responsible for study concept, design, and data collection. G.F. and L.F.M.R. prepared the first draft. G.F., L.F.M.R., A.A.F., G.I.M., and M.F.T.P. drafted and critically revised the manuscript for important intellectual content and gave final approval of the version to be published. 


\section{Funding}

The present research received financial support from British Academy/Newton Foundation grant \#AF160099), Sao Paulo Research Foundation (FAPESP) grant \#2016/22259-4.

\section{Competing interests}

The authors declare no competing interests.

\section{Additional information}

Correspondence and requests for materials should be addressed to G.F.

Reprints and permissions information is available at www.nature.com/reprints.

Publisher's note Springer Nature remains neutral with regard to jurisdictional claims in published maps and institutional affiliations.

(c) (i) Open Access This article is licensed under a Creative Commons Attribution 4.0 International License, which permits use, sharing, adaptation, distribution and reproduction in any medium or format, as long as you give appropriate credit to the original author(s) and the source, provide a link to the Creative Commons licence, and indicate if changes were made. The images or other third party material in this article are included in the article's Creative Commons licence, unless indicated otherwise in a credit line to the material. If material is not included in the article's Creative Commons licence and your intended use is not permitted by statutory regulation or exceeds the permitted use, you will need to obtain permission directly from the copyright holder. To view a copy of this licence, visit http://creativecommons.org/licenses/by/4.0/.

(C) The Author(s) 2021 